\title{
A Mandrel Feeding Strategy in Conical Ring Rolling Process
}

\author{
Wen Meng, Guoqun Zhao, and Yanjin Guan \\ Key Laboratory for Liquid-Solid Structural Evolution and Processing of Materials (Ministry of Education), Shandong University, Jinan, \\ Shandong 250061, China \\ Correspondence should be addressed to Guoqun Zhao; zhaogq@sdu.edu.cn
}

Received 7 January 2014; Revised 12 July 2014; Accepted 20 July 2014; Published 28 September 2014

Academic Editor: Mohamed Djemai

Copyright (C) 2014 Wen Meng et al. This is an open access article distributed under the Creative Commons Attribution License, which permits unrestricted use, distribution, and reproduction in any medium, provided the original work is properly cited.

A mathematical model for radial conical ring rolling with a closed die structure on the top and bottom of driven roll, simplified as RCRRCDS, was established. The plastic penetration and biting-in conditions in RCRRCDS process were determined. A mandrel feeding strategy for RCRRCDS process was proposed. The mandrel feed rate and its reasonable value range were deduced. The coupled thermal-mechanical FE model of RCRRCDS process was established. The reasonable value range of the mandrel feed rate was verified by using numerical simulation method. The results indicate that the reasonable value range of the mandrel feed rate is feasible, the proposed mandrel feeding strategy can realize a steady RCRRCDS process, and the forming quality of conical ring rolled by using the proposed feeding strategy is better than that of conical ring rolled by using a constant mandrel feed rate.

\section{Introduction}

Radial conical ring rolling process with a closed die structure on the top and bottom of driven roll, RCRRCDS, is an advanced plastic forming technology. It has prominent advantages in saving power and material and improving productive efficiency. The rolled seamless conical rings often have better mechanical properties. Therefore, a wide application is found in many industry fields, such as aeronautics, petroleum industry, mechanical industry, wind power, and nuclear power. The typical conical ring products are aeroengine turbine casings, nuclear reactor shells [1], nozzle supports, seals, and flanges [2].

Recently, accurate mathematical modeling and mandrel feeding strategies were mainly investigated due to their key roles in analyzing ring rolling processes. Sun et al. [3] declared that as the mandrel feed rate increases in hot ring rolling process, a more uniform microstructure distribution is obtained. Zhou et al. [4] claimed that as the feed rates of the mandrel and axial rolls increase in radial-axial rectangular ring rolling process, the more uniform strain and temperature distributions of rolled ring can be obtained. In order to reduce the maximum rolling force in radial-axial rectangular ring rolling process, Kim et al. [5] optimally designed the feed rates of the mandrel and axial rolls by using Taguchi method and conjugate gradient method. Wang et al. [6] pointed out that the mandrel feed rate had prominent effects on rolling force and spread distribution in hot ring rolling process. Xu et al. [7] proposed a mathematical model to predict the diameter expansion in radial-axial rectangular ring rolling process and obtained a good agreement between the simulation results and experimental ones. According to the processing map of 42CrMo, Xu et al. [8] designed a reasonable feeding strategy in radial-axial rectangular ring rolling process. To sum up, scholars mainly investigated the effects of mandrel feed rate on rectangular ring rolling processes. However, the studies about mandrel feeding strategy in conical ring rolling process were rarely reported. Therefore, it is necessary to study the mathematical modeling and mandrel feeding strategy in RCRRCDS process.

As conical ring products are widely used, conical ring rolling processes are studied more and more. Yuan [9] mainly simulated a radial-axial conical-like ring rolling process and optimally designed the dimensions of the conical ring blank. The simulation results were in good agreement with the experimental ones in his study. Han et al. [10] optimally designed the dimensions of a conical ring blank in hot rolling process by using numerical simulation and experimental methods. A good agreement between simulation results and experimental ones was observed. Wang et al. [1] proposed 
to adopt a radial-axial conical ring rolling process to manufacture $600 \mathrm{MW}$ nuclear reactor shells. They claimed that simulation results could prove the feasibility of producing the great conical ring by using the proposed ring rolling technology. Usually, in rolling a rectangular ring process, the rolling strategy that would roll a rectangular ring into a dish-shaped one should be avoided, since the dish-shaped ring was regarded as a forming error. But Seitz et al. [2] just utilized this situation and presented a rolling strategy to manufacture a dish-shaped ring from a rectangular ring blank. Their numerical simulation results were in good agreement with experimental ones in their study. However, this rolling strategy was used infrequently in actual ring rolling process.

In summary, up till now, the scholars have mainly studied the optimal design of the dimensions of conical ring blanks. However, they did not discuss how to determine the mandrel feed rate, which has important effects on both the stability of rolling process and the properties of conical rings. Therefore, it is necessary to study the reasonable mandrel feeding strategy in RCRRCDS process.

This paper mainly studied RCRRCDS process by mathematical modeling and numerical simulation methods. In Section 2 of this paper, a mathematical model of RCRRCDS process was established, the mandrel feeding strategy in rolling process was proposed, and the mandrel feed rate and its reasonable value range were deduced. In Section 3, the FE model of RCRRCDS process was set up. In Section 4, the reasonable value range of the mandrel feed rate for a concrete example was studied by using theoretical calculation method; the reasonable value range of the mandrel feed rate was verified by using numerical simulation; the forming quality of the conical ring rolled by using the mandrel feeding strategy proposed in this paper was compared with that of the conical ring rolled by using a constant mandrel feed rate.

\section{Mathematical Modeling of RCRRCDS Process}

2.1. The Plastic Penetration Condition and Biting-In Condition in RCRRCDS Process. Figure 1 shows the schematic diagram of RCRRCDS process at $t$ time. $R_{D}$ and $R_{M}$ are the bottom radii of the driven roll and mandrel, respectively. $R_{t}$ and $r_{t}$ are the ring's bottom-outer- and inner-radii at $t$ time, respectively. $b_{t}$ and $H$ are the thickness and height of the conical ring at $t$ time, respectively. $\theta$ is the intersection angle between the ring wall and $x$-axis; $R_{D}^{\prime}$ and $R_{M}^{\prime}$ are the radii of the driven roll and mandrel at $l$ layer-height, respectively. $R_{t}^{\prime}$ and $r_{t}^{\prime}$ are the ring's outer- and inner-radii at $l$ layer-height and at $t$ time, respectively. $t$ is the rolling time; $l$ is the layerheight of the conical ring. The value ranges of $l, t$, and $H$ are $(0 \leq l \leq H),\left(0 \leq t \leq T_{\text {total }}\right)$, and $\left(0<H \leq R_{M} \tan \theta\right)$, respectively. $T_{\text {total }}$ is the total rolling time.

Figure 2 shows the schematic diagram of RCRRCDS process at $l$ layer-height and at $t$ time. $\mathrm{O}_{1}, \mathrm{O}_{2}$, and $\mathrm{O}_{3}$ are the centers of the driven roll and mandrel and conical ring, respectively. $\Delta h_{D}(l, t)$ and $\Delta h_{M}(l, t)$ are the feed amounts per revolution of the driven roll and mandrel at $l$ layer-height and

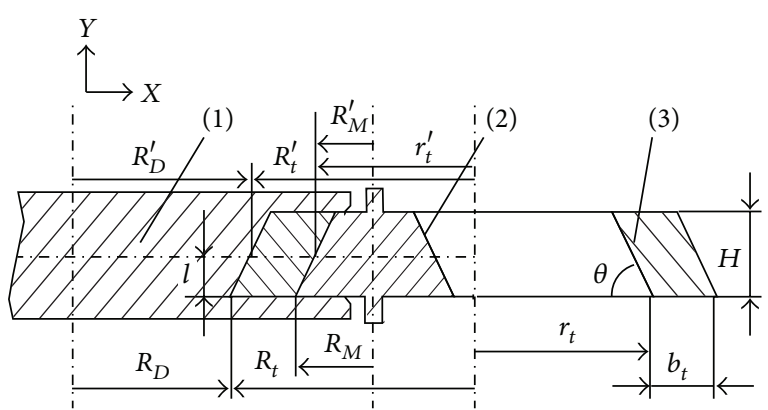

(1) Driven roll

(2) Mandrel

(3) Conical ring

Figure 1: The schematic diagram of the modification of ring's volume in mathematical model of RCRRCDS process.

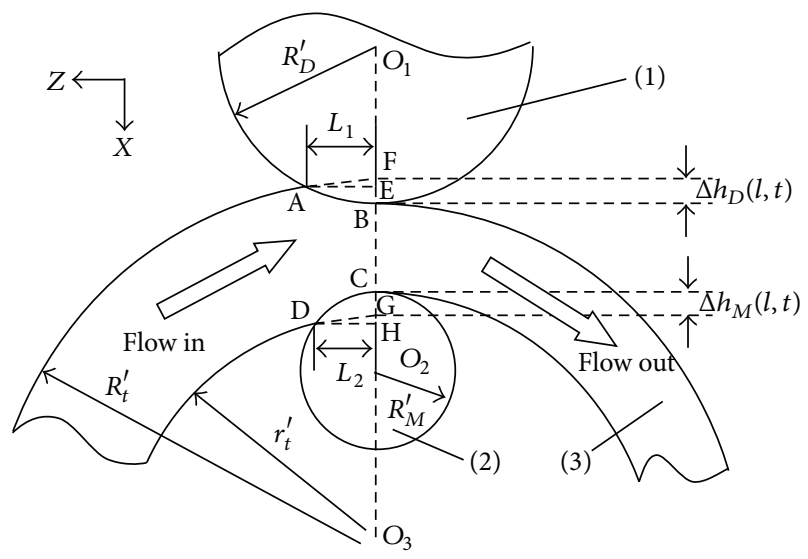

(1) Driven roll

(2) Mandrel

(3) Conical ring

FIgURE 2: The schematic diagram of RCRRCDS process at $t$ time.

at $t$ time, respectively. $L_{1}$ is the projected length of the contact circular arc $A B$ between the conical ring and driven roll on $z$ axis. $L_{2}$ is the projected length of the contact circular arc $C D$ between the conical ring and mandrel on $z$-axis.

In RCRRCDS process, since the conical ring suffers the rolling forces of the driven roll and mandrel and the resistance force of the top and bottom parts of the driven roll, the conical ring's radius continuously increases while its height is invariable. Therefore, it is reasonable to deduce the plastic penetration and biting-in conditions for RCRRCDS process by using the plastic penetration and biting-in conditions for plain ring rolling process presented by Hua et al. [11] as the beginning conditions. It must be noticed that, under the plastic penetration and biting-in conditions for plain ring rolling process, the radii of the driven roll and mandrel are both treated as constants and the inner and outer radii of ring are both treated as the function of rolling time $t$. However, under the plastic penetration and biting-in conditions at $t$ time and at $l$ layer-height in RCRRCDS process, the radii 


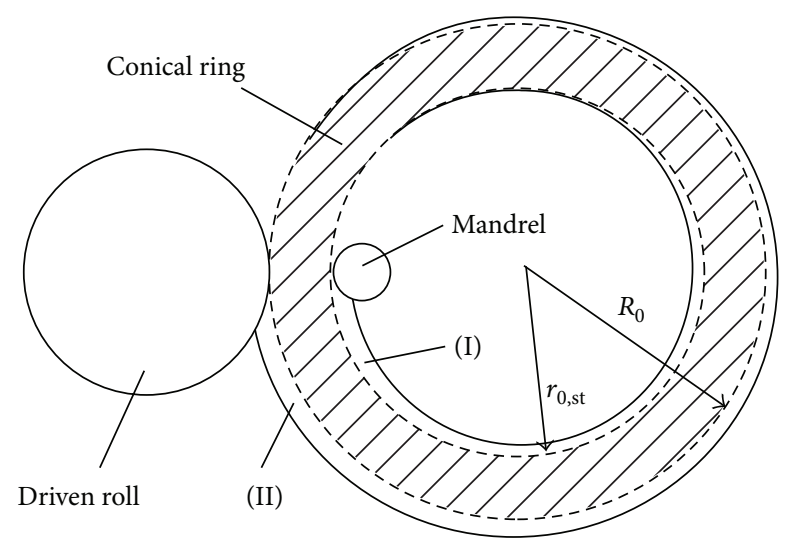

FIGURE 3: The schematic diagram of RCRRCDS process at $l$ layerheight and $t$ time.

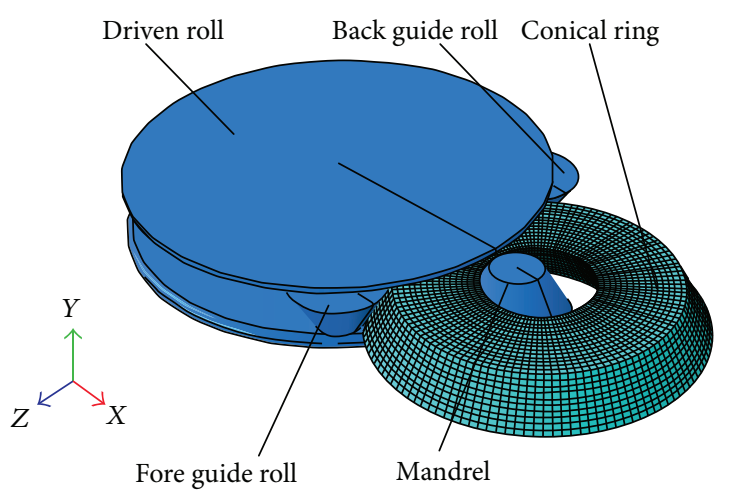

Figure 4: The FE model of RCRRCDS process.

of driven roll and mandrel are both treated as the functions of layer-height $l$, and the inner and outer radii of ring are treated as the functions of both rolling time $t$ and layer-height $l$. In this way, the plastic penetration and biting-in conditions at $t$ time and at $l$ layer-height in RCRRCDS process can be established as follows:

$$
\begin{aligned}
\Delta h_{\min } & (l, t) \\
& =6.55 \times 10^{-3}\left(R_{t}^{\prime}-r_{t}^{\prime}\right)^{2}\left(\frac{1}{R_{D}^{\prime}}+\frac{1}{R_{M}^{\prime}}+\frac{1}{R_{t}^{\prime}}-\frac{1}{r_{t}^{\prime}}\right),
\end{aligned}
$$

$$
\begin{aligned}
\Delta h_{\max } & (l, t) \\
= & \frac{2 \beta^{2}}{\left(1 / R_{D}^{\prime}+1 / R_{M}^{\prime}\right)^{2}}\left(\frac{1}{R_{D}^{\prime}}+\frac{1}{R_{M}^{\prime}}+\frac{1}{R_{t}^{\prime}}-\frac{1}{r_{t}^{\prime}}\right), \\
& \Delta h_{\min }(l, t) \leq \Delta h(l, t) \leq \Delta h_{\max }(l, t),
\end{aligned}
$$

where $\Delta h(l, t)$ is the feed amount per revolution at $l$ layerheight and at $t$ time; $\Delta h_{\min }(l, t)$ and $\Delta h_{\max }(l, t)$ are the permitted minimum and maximum of $\Delta h(l, t)$, respectively; $\beta$ is the friction angle between the conical ring and rolls; $R_{D}^{\prime}=R_{D}+l \cot \theta, R_{M}^{\prime}=R_{M}-l \cot \theta, R_{t}^{\prime}=R_{t}-l \cot \theta$, and $r_{t}^{\prime}=r_{t}-l \cot \theta$.
In order to make the conical ring completely forged penetration and simultaneously bit into the roll gap between the driven roll and mandrel, according to (1)-(3), the feed amount per revolution at $l$ layer-height and at $t$ time, $\Delta h(l, t)$, should satisfy the following equation:

$$
\left[\Delta h_{\min }(l, t)\right]_{\max } \leq \Delta h(l, t) \leq\left[\Delta h_{\max }(l, t)\right]_{\min },
$$

where $\left[\Delta h_{\min }(l, t)\right]_{\max }$ is the maximum value of $\Delta h_{\min }(l, t)$ at $t$ time; $\left[\Delta h_{\max }(l, t)\right]_{\min }$ is the minimum value of $\Delta h_{\max }(l, t)$ at $t$ time. If ignoring the smaller term $1 / R_{t}^{\prime}-1 / r_{t}^{\prime}$ in (2) and (3), according to the monotonicity of functions $\Delta h_{\min }(l, t)$ and $\Delta h_{\max }(l, t)$, the maximum of function $\Delta h_{\min }(l, t)$ and the minimum of function $\Delta h_{\max }(l, t)$ can be obtained at $l=H$ as follows:

$$
\begin{aligned}
& {\left[\Delta h_{\min }(l, t)\right]_{\max }=\Delta h_{\min }(l=H, t),} \\
& {\left[\Delta h_{\max }(l, t)\right]_{\text {min }}=\Delta h_{\text {max }}(l=H, t) .}
\end{aligned}
$$

2.2. The Reasonable Value Range of Mandrel Feed Rate. Determining a reasonable feeding strategy is the precondition of realizing a steady rolling process. To realize a steady and feasible radial-axial rectangular ring rolling process, the feeding strategy that can achieve a constant ring's outerradius-growth-rate was adopted by Guo and Yang [12], Pan [13], and Kim et al. [14], respectively. However, the mandrel feeding strategy deduced by them can only be used in radialaxial rectangular ring rolling processes but cannot be directly used in conical ring rolling process. For this reason, this paper deduced the mandrel feed rate and its reasonable value range by adopting the feeding strategy that can realize a constant ring's outer-radius-growth-rate. Moreover, they did not consider the effects of the changes of ring's wall thickness on its volume changes at a certain time in rolling process. The change of ring's wall thickness has significant effect on the control accuracy of rolls' motions in rolling process. Therefore, this paper considered the effect of the change of conical ring's wall thickness on ring's volume in the established mathematical model of RCRRCDS process.

Generally, the whole rolling process is divided into four rolling stages, the initial biting-in stage, steady forming stage, final rolling stage, and roundness correction stage. In the mathematical model of RCRRCDS process established in this paper, the initial biting-in stage is from the time that the mandrel starts to roll the ring to the time that the ring just right rotates the first one revolution. The steady forming stage is from the end of the initial biting-in stage to the time that the mandrel stops feed movement. The final rolling stage is from the end of the steady forming stage to the time that the mandrel goes on ring rolling another one revolution. The roundness correction stage is from the end of the final rolling stage to the time that the mandrel goes on ring rolling additional two revolutions. The ring is bit into the gap between the driven roll and mandrel in the initial biting-in stage at first, then deformed steadily in the steady forming stage, and finally rolled into a round and plain ring in the final rolling stage and the roundness correction stage. Thus, 


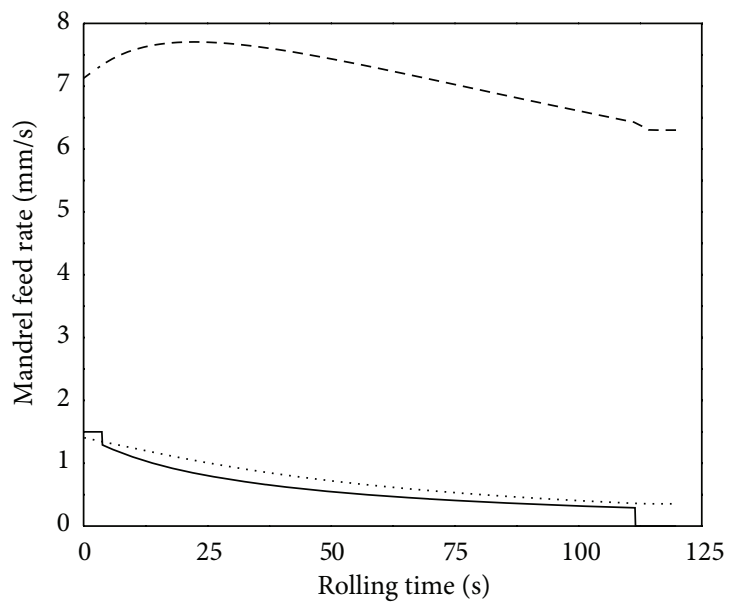

(a)

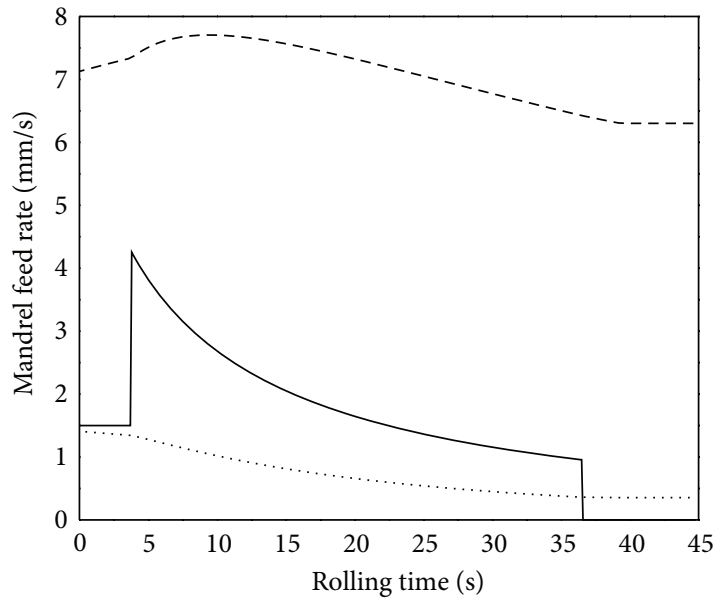

(c)

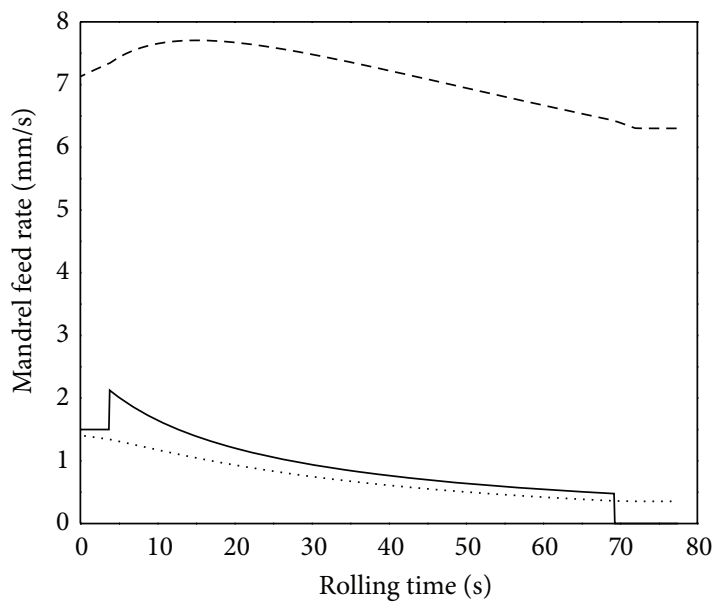

(b)

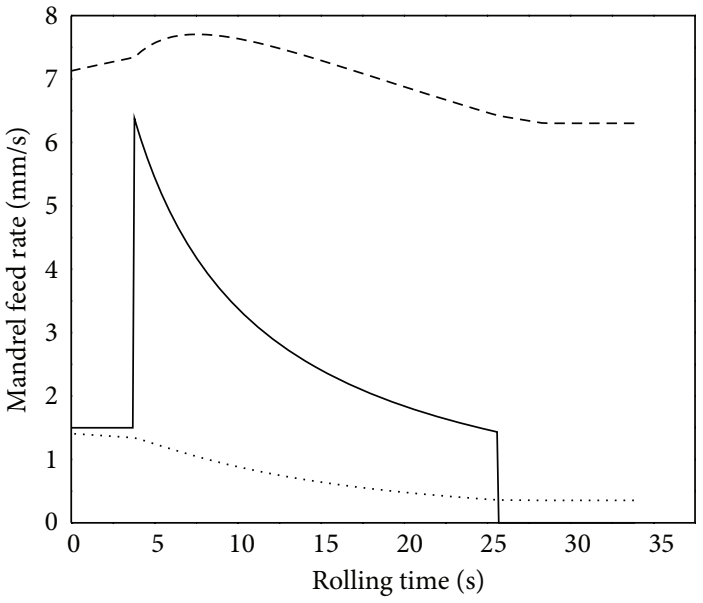

(d)

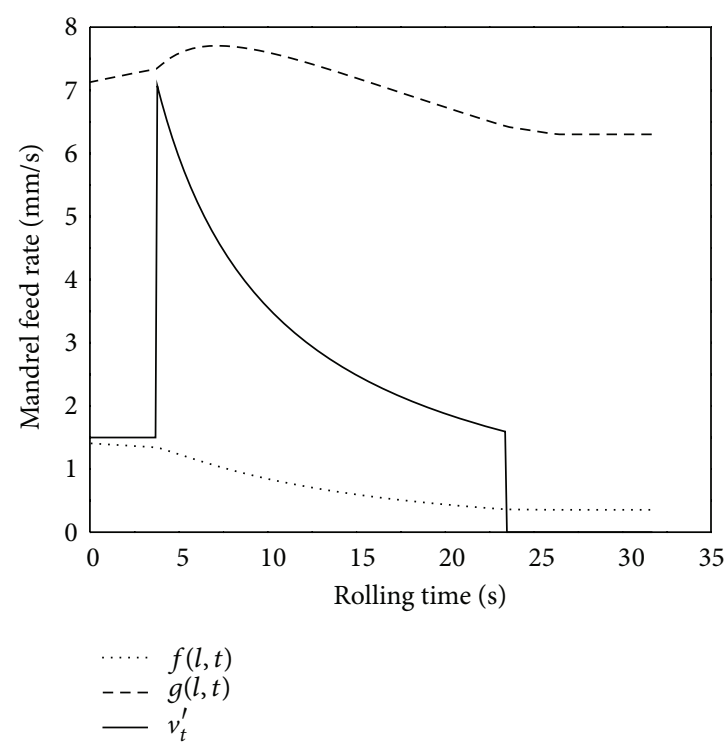

(e)

Figure 5: The changing curves of $v_{t}^{\prime}, f(l, t)$, and $g(l, t)$ with rolling time. (a) $v_{R}=1.215 \mathrm{~mm} / \mathrm{s} ;(\mathrm{b}) v_{R}=2 \mathrm{~mm} / \mathrm{s} ;(\mathrm{c}) v_{R}=4 \mathrm{~mm} / \mathrm{s}$; (d) $v_{R}=6 \mathrm{~mm} / \mathrm{s}$; (e) $v_{R}=6.65 \mathrm{~mm} / \mathrm{s}$. 


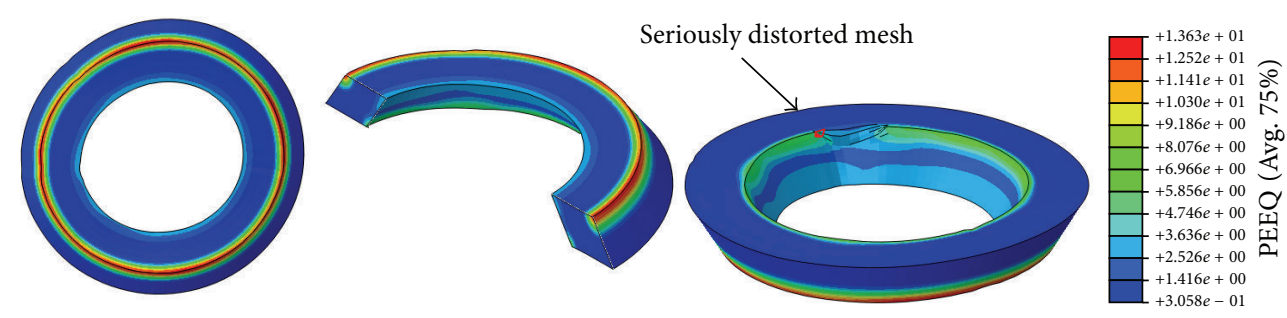

FIGURE 6: Simulation results when $v_{R}$ is selected as $1.215 \mathrm{~mm} / \mathrm{s}$ in RCRRCDS process.
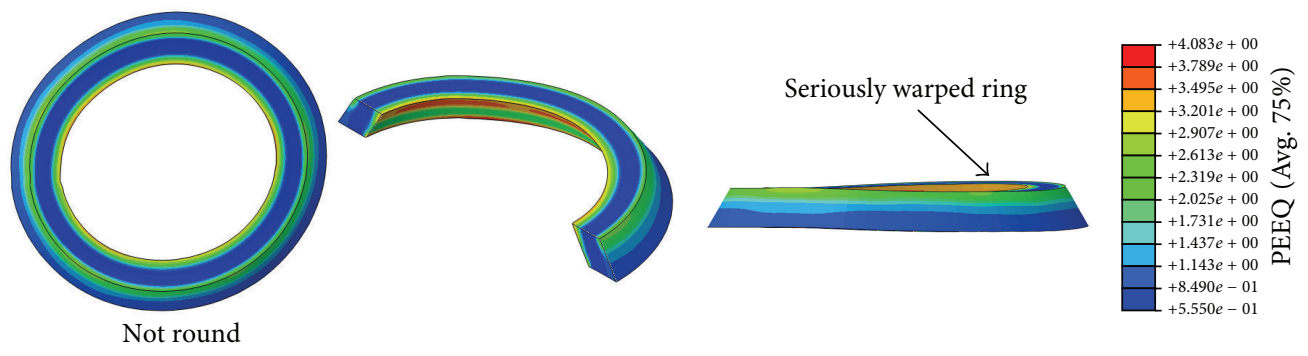

Figure 7: Simulation results when $v_{R}$ is selected as $6.65 \mathrm{~mm} / \mathrm{s}$ in RCRRCDS process.

the total time of RCRRCDS process, $T_{\text {total }}$, can be expressed as follows:

$$
T_{\text {total }}=\Delta T_{\text {in }}+\Delta T_{\text {st }}+\Delta T_{\text {fi }}+\Delta T_{\text {mod }},
$$

where $\Delta T_{\text {in }}, \Delta T_{\text {st }}, \Delta T_{\text {fi }}$, and $\Delta T_{\text {mod }}$ are the time of the initial biting-in stage, steady forming stage, final rolling stage, and roundness correction stage, respectively.

The mandrel feeding strategy proposed in this paper is that an appropriate constant mandrel feed rate, $v_{t, \text { in }}$, is firstly employed in the initial biting-in stage; then a constant ring's bottom-outer-radius-growth-rate is adopted in the steady forming stage based on the plastic penetration and biting-in conditions of RCRRCDS process.

2.2.1. The Initial Biting-In Stage. The initial conical ring blank is a regular conical ring. Its volume is $V_{\text {initial }}$. By considering the complexity of the RCRRCDS process, this paper makes several reasonable assumptions to the mathematical model of RCRRCDS process. By considering that the conical ring is rotated from quiescent state at the start time of rolling process, the first assumption is that the peripheral speed of driven roll's bottom, $v_{D}$, is constant and the peripheral speed of ring's bottom-outer-radius gradually grows up from 0 to $v_{D}$ in the initial biting-in stage at a constant acceleration. Based on the assumption, we can get the rolling time of the initial biting-in stage as follows:

$$
\Delta T_{\text {in }}=\frac{4 \pi R_{0}}{v_{D}} .
$$

2.2.2. Steady Forming Stage. Since the constant mandrel feed rate, $v_{t, \text { in }}$, is very small and $\Delta T_{\text {in }}$ is very short in the initial biting-in stage, the ring's outer-radius is basically unchanged. Therefore, the second assumption is that the ring's bottom-outer-radius is unchanged but its inner-radius slowly increases in the initial biting-in stage. According to the second assumption, the conical ring's bottom-inner-radius at the initial time of steady forming stage, $r_{0, s t}$, can be got as follows:

$$
r_{0, \mathrm{st}}=r_{0}+v_{t, \mathrm{in}} \Delta T_{\mathrm{in}} .
$$

The third assumption is that the conical ring blank is treated as a regular conical ring in the steady forming stage and the ring's volume at the start of steady forming stage is a modified one. That is to say, the ring cross section shapes are equal at arbitrary time and at different positions in peripheral direction. In the actual steady forming stage, there exist certain differences of shapes and areas between the cross sections of the ring at different positions in peripheral direction, as shown in Figure 3. Because of the continuous and gradual deformation process, there always exists some metal that does not contribute to the ring's radius-growth, as shown as the blank areas I and II in Figure 3.

Therefore, in order to control the rolling process accurately, it is necessary to consider the effect of the metal volume of these two areas on the rolling process. Thus, the volume of ring is modified as $V_{\text {initial,st }}$, and it is expressed as

$$
\begin{aligned}
V_{\text {inital }, \mathrm{st}}= & {\left[\frac{1}{3} \pi R_{0}^{3} \tan \theta-\frac{1}{3} \pi\left(R_{0}-H \cot \theta\right)^{3} \tan \theta\right] } \\
& -\left[\frac{1}{3} \pi r_{0, \mathrm{st}}^{3} \tan \theta-\frac{1}{3} \pi\left(r_{0, \mathrm{st}}-H \cot \theta\right)^{3} \tan \theta\right], \\
V_{t, \mathrm{st}}= & {\left[\frac{1}{3} \pi R_{t, \mathrm{st}}^{3} \tan \theta-\frac{1}{3} \pi\left(R_{t, \mathrm{st}}-H \cot \theta\right)^{3} \tan \theta\right] } \\
& -\left[\frac{1}{3} \pi r_{t, \mathrm{st}}^{3} \tan \theta-\frac{1}{3} \pi\left(r_{t, \mathrm{st}}-H \cot \theta\right)^{3} \tan \theta\right],
\end{aligned}
$$

where $V_{\text {initial,st }}$ is the ring's volume at the initial time of steady forming stage; $V_{t, \mathrm{st}}$ is the instantaneous ring's volume in 


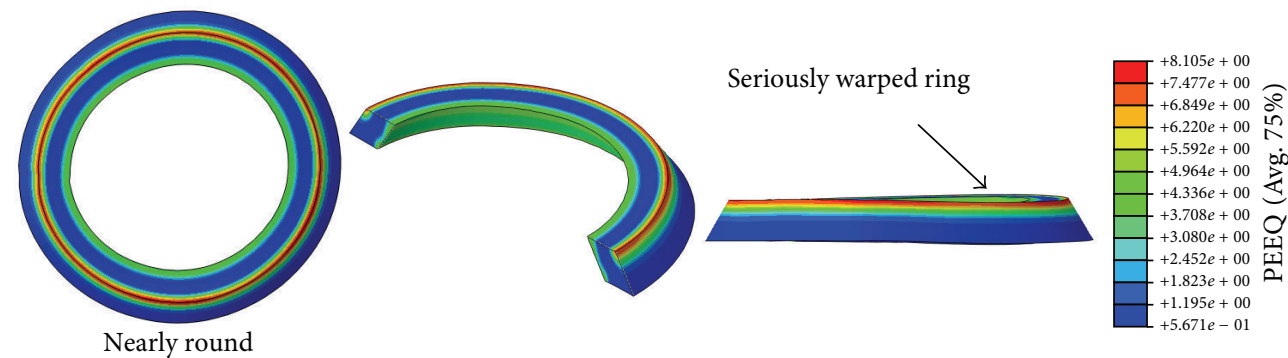

FigURE 8: Simulation results when $v_{R}$ is selected as $2 \mathrm{~mm} / \mathrm{s}$ in RCRRCDS process.

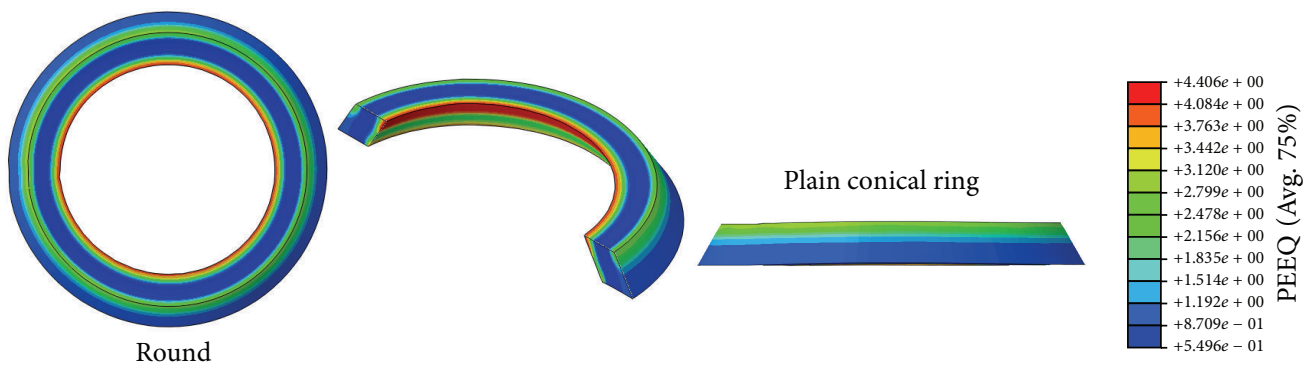

FIGURE 9: Simulation results when $v_{R}$ is selected as $4 \mathrm{~mm} / \mathrm{s}$ in RCRRCDS process.

steady forming stage; $R_{t, \text { st }}$ is the instantaneous bottom-outerradius of the conical ring in steady forming stage; $r_{t, \mathrm{st}}$ is the instantaneous bottom-inner-radius of the conical ring in steady forming stage.

According to the principle of volume constancy, $R_{t, \mathrm{st}}$ can be expressed as follows:

$$
R_{t, \mathrm{st}}=\frac{b_{t, \mathrm{st}}}{2}+\frac{b_{0, \mathrm{st}}\left(R_{0}+r_{0, \mathrm{st}}-H \cot \theta\right)}{2 b_{t, \mathrm{st}}}+\frac{H \cot \theta}{2}
$$

where $b_{0, \mathrm{st}}=R_{0, \mathrm{st}}-r_{0, \mathrm{st}}, b_{t, \mathrm{st}}=R_{t, \mathrm{st}}-r_{t, \mathrm{st}}$, and $b_{t, \mathrm{st}}=b_{0, \mathrm{st}}-$ $\int_{0}^{t} v_{t, \mathrm{st}} d t . b_{0, \mathrm{st}}$ is the thickness of the ring wall at the initial time of steady forming stage; $R_{0, \mathrm{st}}$ is the bottom-outer-radius of the conical ring at the initial time of steady forming stage and it is equal to $R_{0} ; b_{t, \mathrm{st}}$ is the instantaneous thickness of the ring wall in steady forming stage; $v_{t, \mathrm{st}}$ is the instantaneous mandrel feed rate in steady forming stage.

The constant outer-radius-growth-rate of ring's bottom, $v_{R}$, is adopted in the steady forming stage in RCRRCDS process. So $R_{t, \mathrm{st}}$ and $\Delta T_{\mathrm{st}}$ can be expressed as follows:

$$
\begin{aligned}
& R_{t, \mathrm{st}}=R_{0}+v_{R} t, \\
& \Delta T_{\mathrm{st}}=\frac{\left(R_{f, \mathrm{st}}-R_{0}\right)}{v_{R}},
\end{aligned}
$$

where $R_{f, s t}$ is the bottom-outer-radius of the conical ring at the final time of steady forming stage.
Because the derivative of $R_{t, \mathrm{st}}$ with respect to $t$ is $v_{R}$, taking the derivative of (10) with respect to $t$, the following equations can be obtained:

$$
\begin{aligned}
v_{R} & =\frac{d R_{t, \mathrm{st}}}{d t}=\frac{v_{t, \mathrm{st}}}{2}\left[\frac{\left(R_{0}+r_{0, \mathrm{st}}-H \cot \theta\right) b_{0, \mathrm{st}}}{b_{t, \mathrm{st}}^{2}}-1\right], \\
v_{t, \mathrm{st}} & =\frac{2 v_{R}}{\left(\left(R_{0}+r_{0, \mathrm{st}}-H \cot \theta\right) b_{0, \mathrm{st}} / b_{t, \mathrm{st}}^{2}\right)-1} .
\end{aligned}
$$

2.2.3. The Final Rolling Stage. In the final rolling stage, the mandrel stops the feed movement but the thicknesses of the ring wall at different positions in peripheral direction gradually turn to be equal. In Figure 3, because the metal volume of the blank areas as shown as I and II is ignored in the steady forming stage according to the third assumption, the effect of the ignored metal volume on the ring's radius growth must be considered in the final rolling stage. After considering the contribution of the ignored metal volume to the ring's radius growth, the fourth assumption is that the ring's bottom-outer-radius grows from $R_{f \text {,st }}$ to $R_{f}$ in a constant velocity in the final rolling stage and that the conical ring blank is finally deformed into a regular one. That is to say, all of the metal volume is contributed to the ring's radius growth. Therefore, according to incompressibility, $R_{f}$ can be calculated by the initial ring's volume, $V_{\text {initial }}$. So we get

$$
\begin{gathered}
R_{f}=\frac{b_{0}\left(R_{0}+r_{0}-H \cot \theta\right)}{2 b_{f}}+\frac{b_{0}}{2}+\frac{H \cot \theta}{2}, \\
\Delta T_{\mathrm{fi}}=\frac{2 \pi R_{f}}{v_{D}},
\end{gathered}
$$




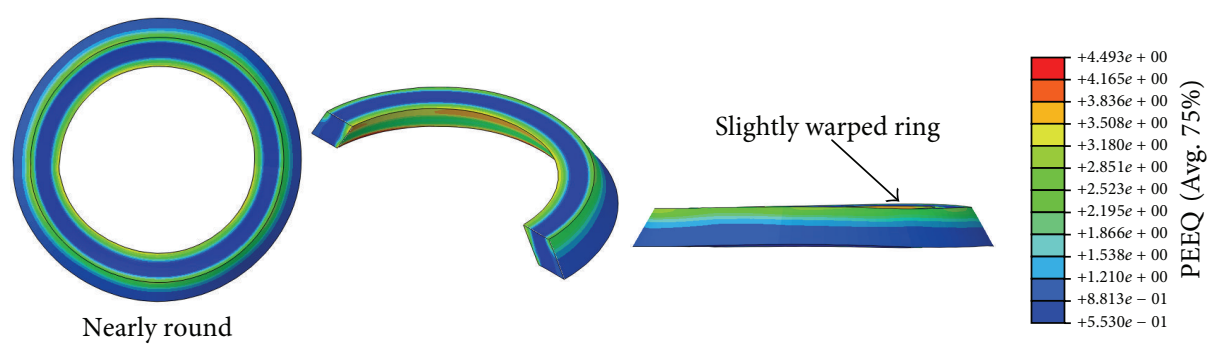

FIGURE 10: Simulation results when $v_{R}$ is selected as $6 \mathrm{~mm} / \mathrm{s}$ in RCRRCDS process.

where $R_{f}$ is the final bottom-outer-radius of the conical ring; $b_{0}$ and $b_{f}$ are the initial and final thickness of the ring wall, respectively.

2.2.4. Roundness Correction Stage. In the roundness correction stage, the mandrel goes on ring rolling additional two revolutions to make the ring round. The rolling time of this stage can be expressed as follows:

$$
\Delta T_{\bmod }=\frac{4 \pi R_{f}}{v_{D}} .
$$

To sum up, according to the above studies, the instantaneous ring's bottom-outer-radius and the instantaneous mandrel feed rate can be finally expressed as follows:

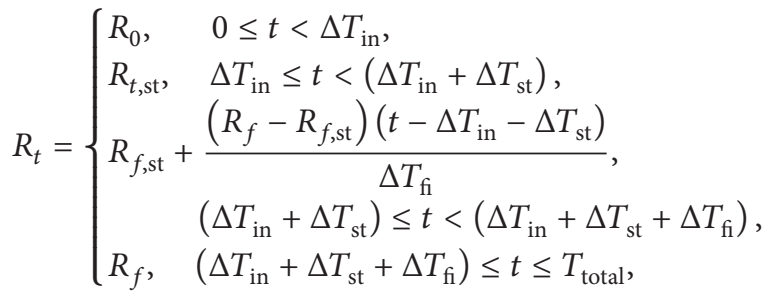

$$
\begin{aligned}
& v_{t}^{\prime}=\left\{\begin{array}{c}
v_{t, \text { in }}, \quad 0 \leq t<\Delta T_{\text {in }}, \\
\frac{2 v_{R}}{\left(\left(R_{0}+r_{0, \text { st }}-H \cot \theta\right) b_{0, \text { st }} / b_{t, \mathrm{st}}^{2}\right)-1}, \\
\Delta T_{\text {in }} \leq t<\left(\Delta T_{\text {in }}+\Delta T_{\text {st }}\right), \\
0, \quad\left(\Delta T_{\text {in }}+\Delta T_{\text {st }}\right) \leq t \leq T_{\text {total }} .
\end{array}\right.
\end{aligned}
$$

2.3. Reasonable Value Range of the Mandrel Feed Rate. Assume that there is no sliding motion between the rolls and ring in a steady RCRRCDS process. At $t$ time of the rolling process, the length that the ring's outer-radius at $l$ layer-height rotates in just one revolution is equal to the length that the radius of the driven roll at $l$ layer-height rotates. Therefore, we have

$$
2 \pi R_{t}^{\prime}=n_{D} R_{D}^{\prime} \Delta t
$$

where $n_{D}$ is the angle speed of the driven roll; $\Delta t$ is the needed time when the conical ring rotates one revolution at $t$ time in steady forming stage.
The mandrel feed rate at $l$ layer-height and at $t$ time, $v_{t}^{\prime}$, can be approximately expressed as

$$
v_{t}^{\prime} \approx \frac{\Delta h(l, t)}{\Delta t}
$$

In terms of (4), (20), and (21), we can get

$$
\frac{n_{D} R_{D}^{\prime}\left[\Delta h_{\min }(l, t)\right]_{\max }}{2 \pi R_{t}^{\prime}} \leq v_{t}^{\prime} \leq \frac{n_{D} R_{D}^{\prime}\left[\Delta h_{\max }(l, t)\right]_{\min }}{2 \pi R_{t}^{\prime}} .
$$

For convenience, a qualified function of the minimum instantaneous mandrel feed rate, $f(l, t)$, and a qualified function of the maximum instantaneous mandrel feed rate, $g(l, t)$, are defined to determine the reasonable value range of $v_{t}^{\prime}$ in RCRRCDS process, and they are expressed as

$$
\begin{aligned}
& f(l, t)=\frac{n_{D} R_{D}^{\prime}\left[\Delta h_{\min }(l, t)\right]_{\max }}{2 \pi R_{t}^{\prime}}, \\
& g(l, t)=\frac{n_{D} R_{D}^{\prime} \Delta\left[h_{\max }(l, t)\right]_{\min }}{2 \pi R_{t}^{\prime}} .
\end{aligned}
$$

In terms of (22), (23), and (24), the value range of the instantaneous mandrel feed rate at $l$ layer-height can be determined by the following equation:

$$
f(l, t) \leq v_{t}^{\prime} \leq g(l, t) .
$$

\section{FE Modeling of RCRRCDS Process}

According to the above feeding strategy, this paper established the coupled thermal-mechanical three-dimensional FE model of RCRRCDS process based on ABAQUS/Explicit software, as shown in Figure 4. The technological details about the material constitutive model, contact conditions, meshing, and rolls motion control method are expressed as follows.

3.1. Material Constitutive Model. The material of the conical ring blank used in this paper is Ti-6Al-4V. Its temperaturedependent physical properties, such as thermal conductivity, specific heat, expansion, Young's modulus, and yield stress, are from [15]. Its constitutive model within the forging 


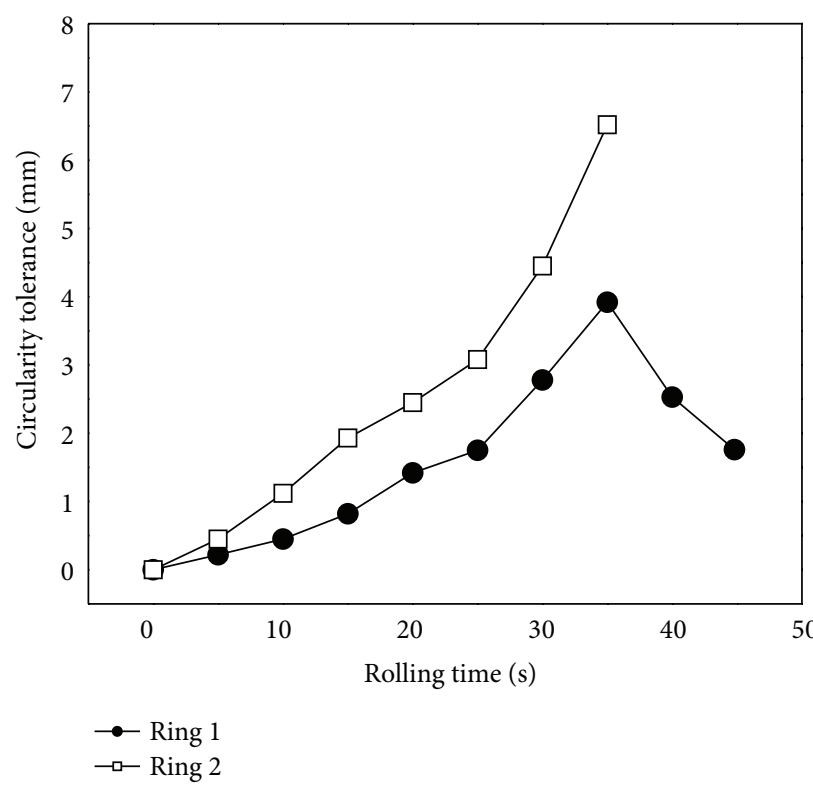

(a)

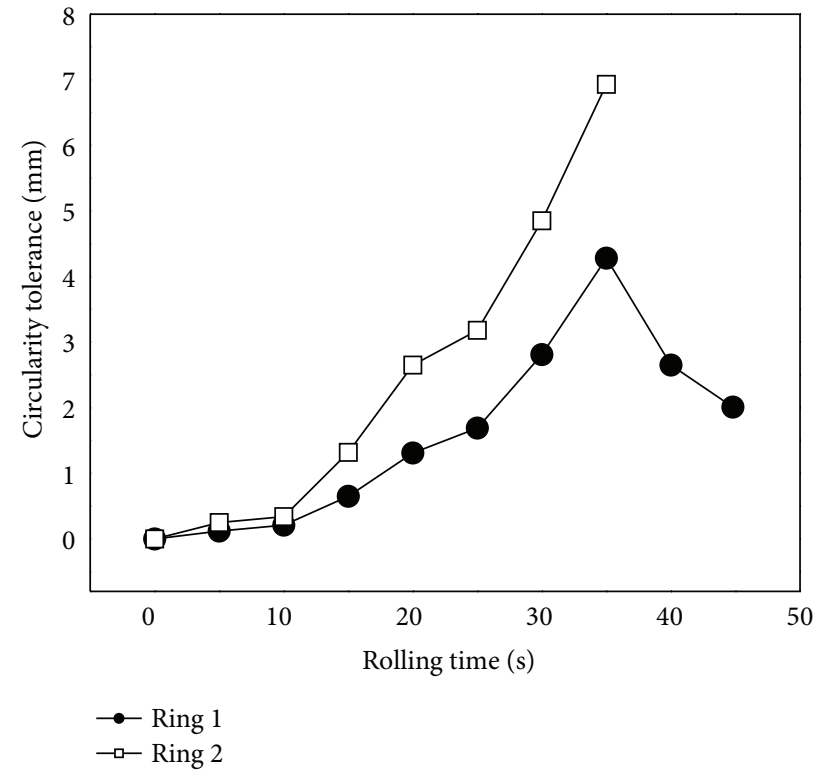

(b)

FIGURE 11: The circularity tolerance of rings 1 and 2 at the bottom of conical ring, (a) inner-radius circle, and (b) outer-radius circle.

TABLE 1: Constitutive data for Ti-6Al-4V.

\begin{tabular}{lc}
\hline Coefficient & Value \\
\hline$k$ & $4.69 \times 10^{-4}$ \\
$m$ & 0.3 \\
$n$ & 1 \\
$\beta$ & 66.73 \\
$\lambda_{0}$ & 6.424 \\
$q$ & $-5.17 \times 10^{-2}$ \\
$\alpha$ & 6.07 \\
$Q_{\text {defm }} / R$ & $5.0668 \times 10^{4}$ \\
\hline
\end{tabular}

temperature range $\left(800^{\circ} \mathrm{C} \sim 950^{\circ} \mathrm{C}\right)$ is expressed as follows [16]:

$$
\begin{aligned}
& \sigma=k Z^{m} \lambda^{n}\left(1-e^{-\beta \varepsilon}\right), \\
& \lambda=\lambda_{0} Z^{q}+\left(1-\lambda_{0} Z^{q}\right) e^{-\alpha \varepsilon}, \\
& Z=\dot{\varepsilon} e^{Q_{\text {defm }} / R T}
\end{aligned}
$$

where $\sigma$ is the flow stress; $Z$ is the Zener-Hollomon parameter; $\lambda$ is an internal state variable; $\varepsilon$ is the plastic strain; $\dot{\varepsilon}$ is the strain rate; $Q_{\text {defm }}$ is the deformation activation energy for $\mathrm{Ti}-6 \mathrm{Al}-4 \mathrm{~V} ; R$ is the universal gas constant; $T$ is the absolute temperature; $k$ is a scaling constant; $m$ is the strain rate sensitivity; $n$ is the structure-stress exponent; $\beta$ is an exponential damping constant relating strain and stress; $\lambda_{0}$ is a scaling constant related to the steady-state stress; $q$ is the rate sensitivity of structure; $\alpha$ is an exponential damping constant relating strain and structure. The values of coefficients are shown in Table 1.
3.2. Friction and Thermal Conditions. Four pairs of contact relationships between the ring and the driven roll, mandrel, and two guide rolls are defined in RCRRCDS process. There exist friction and contact heat conduction at the interface of each contact pair. Surface to surface contact technology is adopted to define the contact relations of each contact pair. Since the glass lubricants are usually used on the top and bottom surfaces of the conical ring to prevent it from being blocked in radial pass, the friction factor between the conical ring and the top and bottom interfaces of driven roll is selected as 0.1 [17]. The friction factor at other interfaces between rolls and conical ring is 0.5 [18]. The contact heat conductivity is $4000 \mathrm{~W} /\left(\mathrm{m}^{2 \circ} \mathrm{C}\right)$ [19]. There exist convection and radiation heat transfer between the ring's outer surfaces and environment in RCRRCDS process. The convection coefficient is $20 \mathrm{~W} /\left(\mathrm{m}^{2 \circ} \mathrm{C}\right)$ [15]. The emissivity is 0.6 [15]. The initial temperature of conical ring blank is $900^{\circ} \mathrm{C}$. The temperature of the driven roll and guide rolls is $100^{\circ} \mathrm{C}$. The temperature of mandrel is $200^{\circ} \mathrm{C}$. The environmental temperature is $20^{\circ} \mathrm{C}$.

3.3. Meshing. Coupled thermal-displacement eight nodes six surfaces element (C3D8RT) is adopted to mesh the conical ring blank. The number of elements is approximately 8,000 . Reduced integration is applied to decrease simulation time, and hourglass control is employed to avoid zeroenergy mode [18]. Since the usage of an appropriate mass scaling factor reduces simulation time and simultaneously maintains the reliability of simulation result [20], the mass scaling factor is selected as 50 in the established FE model. Adaptive remeshing technology is adopted since it can rezone 
TABLE 2: The degrees of freedom of rolls.

\begin{tabular}{|c|c|c|c|c|c|c|}
\hline & \multicolumn{3}{|c|}{$\begin{array}{c}\text { Translational degree } \\
\text { of freedom }\end{array}$} & \multicolumn{3}{|c|}{$\begin{array}{l}\text { Rotational degree of } \\
\text { freedom }\end{array}$} \\
\hline & $X$ & Y & $Z$ & $V R X$ & $V R Y$ & $V R Z$ \\
\hline Driven roll & $\mathrm{F}$ & $\mathrm{F}$ & $\mathrm{F}$ & $\mathrm{F}$ & $\mathrm{A}$ & $\mathrm{F}$ \\
\hline Mandrel & A & $\mathrm{F}$ & F & $\mathrm{F}$ & $\mathrm{U}$ & F \\
\hline $\begin{array}{l}\text { Fore guide } \\
\text { roll }\end{array}$ & A & $\mathrm{F}$ & A & $\mathrm{F}$ & $\mathrm{U}$ & F \\
\hline $\begin{array}{l}\text { Back guide } \\
\text { roll }\end{array}$ & A & $\mathrm{F}$ & A & $\mathrm{F}$ & $\mathrm{U}$ & F \\
\hline
\end{tabular}

Notes. F: fixing; A: amplitude; U: unconstraining.

extremely distorted meshes and make finite element solutions converged easily [21].

3.4. Time Increment. To avoid the iteration nonconvergence of finite element numerical solution, the time increment $\Delta t_{\text {increment }}$ should be smaller than a critical value $\Delta t_{\text {cr }}[1]$ :

$$
\Delta t_{\text {increment }} \leq \Delta t_{\mathrm{cr}}=\frac{l_{\min }}{\sqrt{\rho\left(1-v^{2}\right) / E}}
$$

where $l_{\min }$ is the minimum value of the distance between arbitrary two mesh nodes; $\rho$ is the mass density; $v$ is Poisson's ratio; $E$ is Young's modulus.

3.5. Rolls Motion Controls. The conical ring blank is defined as a deformable body. All rolls are treated as rigid bodies. The conical ring and all rolls are assembled under the global coordinate system, CSYS0. The motion control method of guide rolls in RCRRCDS process is from [13]. Table 2 gives the degrees of freedom of all rolls. $X, Y$, and $Z$ are the translational degrees of freedom of each roll in $x$-, $y$-, and $z$-axis, respectively. $V R X, V R Y$, and $V R Z$ are the rotational degrees of freedom of each roll in $x-, y$-, and $z$-axis. " $F$ " stands for fixing the degree of freedom of the roll. "A" stands for controlling the degree of freedom of the roll by inputting amplitudes. " $U$ " stands for unconstraining the degree of freedom of the roll.

\section{Results and Discussion}

This section simulated and analyzed the reasonable value range of the mandrel feed rate and compared the effect of the mandrel feeding strategy proposed in this paper with the one by using a constant mandrel feed rate on the forming quality of rolled rings in RCRRCDS process. The following three cases are studied.

Case 1. Investigate the reasonable value range of mandrel feed rate in RCRRCDS process by theoretical calculation method. The forming parameters in RCRRCDS process are listed in Table 3. According to the conditions in Table 3 and (25), it can be calculated that the value range of mandrel feed rate is from $1.4 \mathrm{~mm} / \mathrm{s}$ to $7.1 \mathrm{~mm} / \mathrm{s}$ at the initial time of the initial bitingin stage. Therefore, the constant mandrel feed rate can be selected as $1.5 \mathrm{~mm} / \mathrm{s}$ in the initial biting-in stage. According to
TABLE 3: Forming parameters for RCRRCDS process.

\begin{tabular}{lc}
\hline Parameters & Values \\
\hline Bottom radius of driven roll $(\mathrm{mm})$ & 200 \\
Bottom radius of mandrel $(\mathrm{mm})$ & 100 \\
Bottom radius of guide roll $(\mathrm{mm})$ & 40 \\
Initial bottom-outer-radius of ring $(\mathrm{mm})$ & 300 \\
Initial bottom-inner-radius of ring $(\mathrm{mm})$ & 150 \\
Initial height of ring $(\mathrm{mm})$ & 86.5 \\
$\begin{array}{l}\text { Angle between ring wall and horizontal } \\
\text { plane }\left({ }^{\circ}\right)\end{array}$ & 60 \\
Total feed amount of mandrel (mm) & 70 \\
Peripheral speed of driven roll's bottom \\
$(\mathrm{mm} / \mathrm{s})$
\end{tabular}

(6), (16), and (17), it can be calculated that $\Delta T_{\text {in }}=3.77 \mathrm{~s}, \Delta T_{\mathrm{fi}}=$ $2.765 \mathrm{~s}$, and $\Delta T_{\bmod }=5.529 \mathrm{~s}$, respectively. According to (25) and (13), $v_{t}^{\prime}$ should be between $1.341 \mathrm{~mm} / \mathrm{s}$ and $7.341 \mathrm{~mm} / \mathrm{s}$ and $v_{R}$ should be between $1.215 \mathrm{~mm} / \mathrm{s}$ and $6.65 \mathrm{~mm} / \mathrm{s}$ at the start time of the steady forming stage. Therefore, the value of $v_{R}$ is selected as $\{1.215 \mathrm{~mm} / \mathrm{s} ; 2 \mathrm{~mm} / \mathrm{s} ; 4 \mathrm{~mm} / \mathrm{s} ; 6 \mathrm{~mm} / \mathrm{s}$; and $6.65 \mathrm{~mm} / \mathrm{s}\}$, respectively.

Case 2. Validate the reasonable value range of mandrel feed rate in RCRRCDS process by numerical simulation method. The simulation experimental conditions are listed in Table 3. The numerical simulation experiments mainly include three aspects: (1) the mandrel feed rate is smaller than $f(l, t)$ in steady forming stage (select $v_{R}=1.215 \mathrm{~mm} / \mathrm{s}$ ); (2) the mandrel feed rate is between $f(l, t)$ and $g(l, t)$ in steady forming stage (select $v_{R}=2 \mathrm{~mm} / \mathrm{s} ; 4 \mathrm{~mm} / \mathrm{s} ; 6 \mathrm{~mm} / \mathrm{s}$ ); (3) the mandrel feed rate is larger than $g(l, t)$ in steady forming stage (select $v_{R}=6.65 \mathrm{~mm} / \mathrm{s}$ ).

Case 3. Compare the effect of the mandrel feeding strategy proposed in this paper with the one by using a constant mandrel feed rate on the forming quality of rolled rings in RCRRCDS process. Two rings (ring 1 and ring 2) with the same forming parameters are numerically simulated. Ring 1 is carried out by using the constant ring-outer-radiusgrowth-rate proposed in this paper. Ring 2 is carried out by using the constant mandrel feed rate without considering the modification of conical ring's volume and the four forming stages in Section 2.2. The simulation experimental conditions are listed in Table 3 . The constant ring's bottom-outer-radiusgrowth-rate of ring 1 is selected as $4 \mathrm{~mm} / \mathrm{s}$, and the constant mandrel feed rate of ring 2 is selected as $2 \mathrm{~mm} / \mathrm{s}$. According to (6), (7), (12), (16), and (17), the total rolling time of ring 1 is $44.8 \mathrm{~s}$. In this situation, the time of the steady forming stage of ring 1 (approximately $33 \mathrm{~s}$ ) is close to the total rolling time of ring 2 (35s).

Here, the circularity, coaxiality, plainness, and tilting of the rolled conical ring produced by different mandrel feeding strategies in RCRRCDS processes were investigated. The circularity tolerance, $\varepsilon=r_{\max }-r_{\min }$, and coaxial tolerance, $\varphi=\sqrt{\left(x_{0 e}-x_{0 i}\right)^{2}+\left(z_{0 e}-z_{0 i}\right)^{2}}$, presented by Xu et al. [7] 


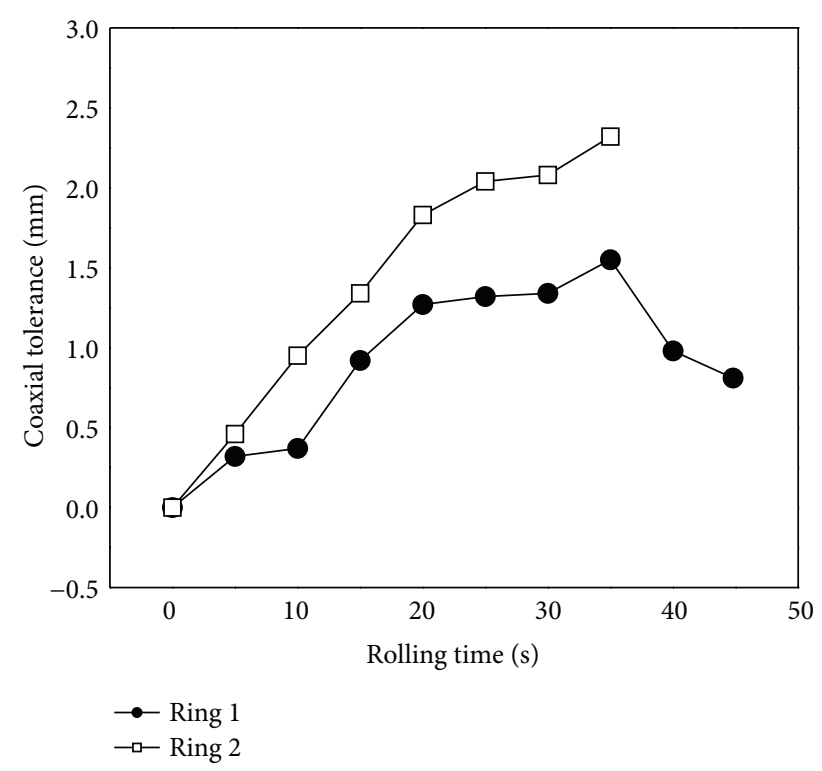

FIgURE 12: The coaxial tolerance of rings 1 and 2 at the bottom of conical ring.

are employed to evaluate the circularity and coaxiality of the rolled ring, where $r_{\max }$ and $r_{\min }$ are the maximum and minimum radii of the rolled ring, respectively. $x_{0 i}$ and $x_{0 e}$ are the $X$ coordinates of the centers of the ring's bottominner- and outer-radii circles, respectively. $z_{0 i}$ and $z_{0 e}$ are the $Z$ coordinates of the centers of the ring's bottom-innerand outer-radii circles, respectively. The plainness tolerance $\psi=(1 / 2) \times\left(\max \left\{y_{i}\right\}+\left|\min \left\{y_{i}\right\}\right|\right)$ is proposed to evaluate the plainness of the rolled ring, where $i$ is the number of nodes at the bottom of conical ring, $y_{i}$ is the $Y$ coordinate of point $i$, and $\max \left\{y_{i}\right\}$ and $\min \left\{y_{i}\right\}$ are the maximum and minimum of $y_{i}$, respectively. The smaller the circularity tolerance, coaxial tolerance, and plainness tolerance of the rolled ring are, the better the circularity, coaxiality, and plainness of the rolled ring are and vice versa.

4.1. Theoretical Calculation for the Reasonable Value Range of Mandrel Feed Rate. Figures 5(a)-5(e) show the changing curves of $v_{t}^{\prime}, f(l, t)$, and $g(l, t)$ with rolling time under different values of $v_{R}$. The $f(l, t)$ and $g(l, t)$ are calculated by (23) and (24), respectively. The $v_{t}^{\prime}$ is calculated by (19). In Figures 5(a)-5(e), $f(l, t)$ gradually decreases in the whole rolling process. The reason may be that as the thickness of ring decreases in rolling process, the ring becomes more easily forged penetration. Moreover, in the initial biting-in stage, $g(l, t)$ gradually increases. This may be because, under the first assumption, as the thickness of ring decreases, the biting-in condition can be satisfied more easily. In the steady forming stage and final rolling stage, $g(l, t)$ firstly increases and then decreases. This may be synthetically caused by the growth of the ring's radius and the reduction of ring's thickness.

It also can be seen from Figures 5(a)-5(e) that, in the initial biting-in stage, the $v_{t}^{\prime}$ remains unchanged and it

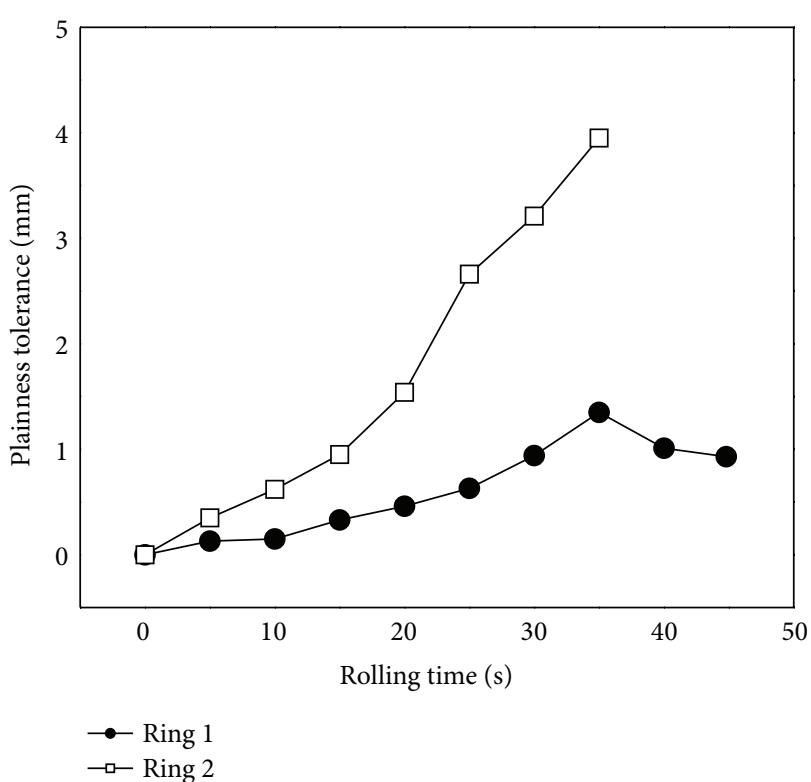

FIgURE 13: The plainness tolerance of rings 1 and 2 at the bottom of conical ring.

is between the minimum instantaneous mandrel feed rate qualified function, $f(l, t)$, and the maximum one, $g(l, t) . v_{t}^{\prime}$ gradually decreases in the steady forming stage. $v_{t}^{\prime}$ is equal to 0 in the final rolling and round correction stages. $v_{t}^{\prime}$ decreases faster than $f(l, t)$ in the steady forming stage. Therefore, in order to make the ring forged penetration, $v_{t}^{\prime}$ should be greater than $f(l, t)$ in the whole steady forming stage. Moreover, it can be seen that the $v_{t}^{\prime}$ decreases faster than $g(l, t)$ in the steady forming stage. Therefore, if $v_{t}^{\prime}$ is smaller than $g(l, t)$ at the beginning time of the steady forming stage, the ring would satisfy the biting-in condition in the following rolling process. This conclusion agrees with the one described in [11] in that once the ring is bit into the roll gap at the start time of rolling process, the biting-in condition can be satisfied in the whole plain rectangular ring rolling process.

In Figure 5(a), when $v_{R}$ is selected as $1.215 \mathrm{~mm} / \mathrm{s}, v_{t}^{\prime}$ is smaller than $f(l, t)$ in the whole steady forming stage. The ring can not be completely forged penetration in rolling process. In this situation, RCRRCDS process can not be theoretically realized. In Figures 5(b)-5(d), when $v_{R}$ is selected as $2 \mathrm{~mm} / \mathrm{s}, 4 \mathrm{~mm} / \mathrm{s}$, and $6 \mathrm{~mm} / \mathrm{s}$, respectively, $v_{t}^{\prime}$ is between $f(l, t)$ and $g(l, t)$ in the whole rolling process. The RCRRCDS process can be realized theoretically. In Figure 5(e), when $v_{R}$ is selected as $6.65 \mathrm{~mm} / \mathrm{s}, v_{t}^{\prime}$ is close to $g(l, t)$ at the initial time of steady forming stage. The ring is difficultly bit into the roll gap. In this situation, RCRRCDS process is difficultly carried out theoretically.

To sum up, to realize the steady forming of RCRRCDS process, $v_{t}^{\prime}$ should be between $f(l, t)$ and $g(l, t)$ in the whole rolling process. If $v_{t}^{\prime}$ is smaller than $f(l, t)$ or near to $f(l, t)$, the ring will be difficultly forged penetration in rolling process. If $v_{t}^{\prime}$ is bigger than $g(l, t)$ or near to $g(l, t)$, the ring will be difficultly bit into the roll gap in rolling process. 


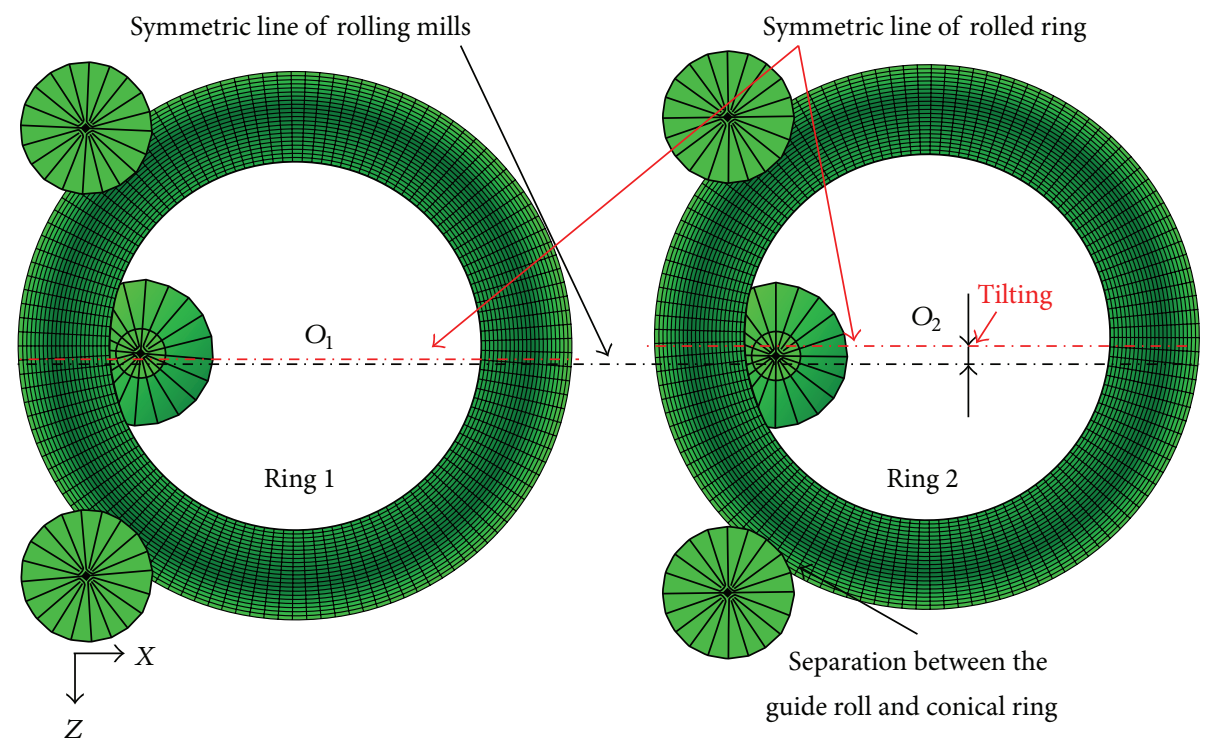

FIgURE 14: The comparison of match degree.

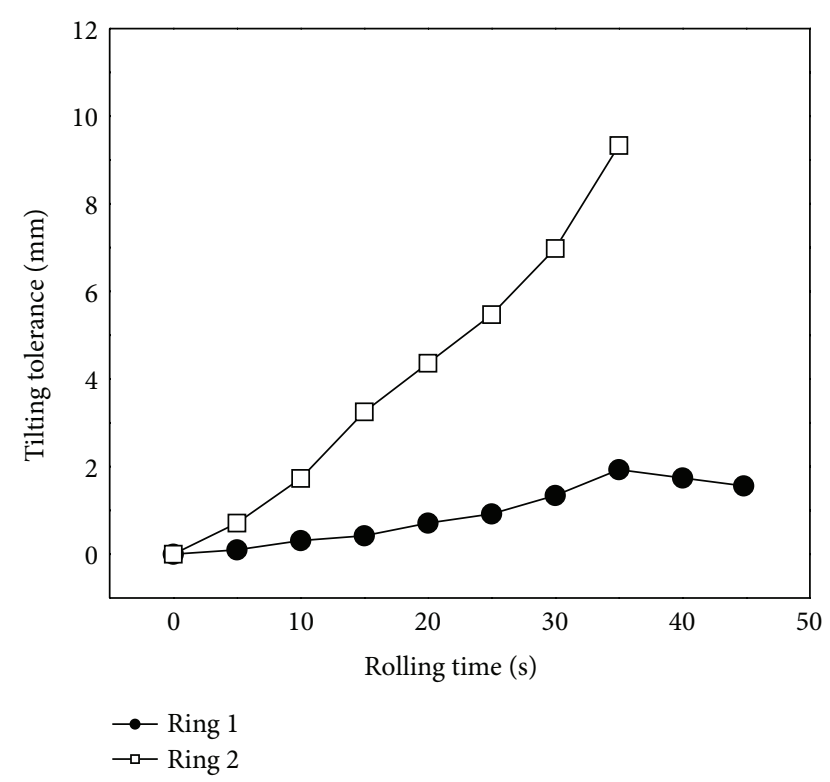

FIgURE 15: The tilting tolerance of rings 1 and 2.

4.2. Numerical Simulation Validation for the Reasonable Value Range of Mandrel Feed Rate. In order to validate the reasonable value range of mandrel feed rate, the effect of different mandrel feed rates on the roundness and plainness of the rolled ring was studied according to the FE model of RCRRCDS process established in Section 3. Figure 6 shows the simulation results when $v_{R}$ is selected as $1.215 \mathrm{~mm} / \mathrm{s}$. In Figure 6, the values of equivalent strain (PEEQ) at the outer and inner surfaces of the conical ring are larger than those at other positions. This indicates that the deformation of the conical ring mainly concentrates upon its outer and inner surfaces. When RCRRCDS process proceeds to the 61.3th second, the mesh elements of 9120 and 9216 are seriously distorted, as shown in Figure 6, and the simulation process stops. The reason for this phenomenon is that since the feed amount per revolution is too small in RCRRCDS process, the conical ring can not be completely forged penetration. In this case, the radius of ring cannot smoothly increase. The ring is gradually distorted as the rolling process proceeds. Finally, the RCRRCDS process fails.

Figure 7 shows the simulation results when $v_{R}$ is selected as $6.65 \mathrm{~mm} / \mathrm{s}$. In this case, the conical ring is rolled into a seriously warped and no-round conical ring. The main reason is that since the feed amount per revolution is too large, the ring can hardly be bit into the roll gap.

Figures 8,9 , and 10 show the simulation results when $v_{R}$ is selected as $2 \mathrm{~mm} / \mathrm{s}, 4 \mathrm{~mm} / \mathrm{s}$, and $6 \mathrm{~mm} / \mathrm{s}$, respectively. These RCRRCDS processes are successfully carried out. The simulation results can prove in theory that when the mandrel feed rate is between $f(l, t)$ and $g(l, t)$, the conical rings can be successfully rolled. Furthermore, in Figures 8-10, when $v_{R}$ is selected as $2 \mathrm{~mm} / \mathrm{s}$, the ring is rolled into a nearly round but severely warped ring; when $v_{R}$ is selected as $4 \mathrm{~mm} / \mathrm{s}$, the ring is rolled into a round and plain ring; when $v_{R}$ is selected as $6 \mathrm{~mm} / \mathrm{s}$, the ring is rolled into a nearly round and slightly warped ring. This indicates that a round and plain ring can be successfully obtained when $v_{R}$ is between $2 \mathrm{~mm} / \mathrm{s}$ and $6 \mathrm{~mm} / \mathrm{s}$. For the concrete example in Section 4.2, the numerical simulation results proved that the better value of $v_{R}$ is $4 \mathrm{~mm} / \mathrm{s}$.

\subsection{The Effects of Different Feeding Strategies on Forming Quality of Rolled Ring in RCRRCDS Process}

4.3.1. Circularity. The circularity is an important factor for evaluating the forming quality of rolled ring. A small circularity tolerance is of benefit to saving material and shortening production cycle. Figure 11 compared the circularity tolerance of ring 1 with that of ring 2 . It indicates that the circularity 
forming quality of ring 1 is better than that of ring 2 . The circularity tolerance of ring 1 increases gradually in the initial biting-in stage and steady forming stage and then decreases in the final rolling stage and round correction stage. This phenomenon is because of the fact that as the rolling time increases in the initial stage and steady forming stage, the incremental deformation of the ring in simulation process causes the rolled ring to be less round, while the mandrel stops feeding motion in the final rolling stage and round correction stage and thus the roundness of conical ring is corrected to some extent. The circularity tolerance of ring 2 gradually increases since its roundness is not appropriately corrected in rolling process. In this situation, as the rolling time increases, the roundness of ring 2 gradually becomes worse.

4.3.2. Coaxiality. Coaxiality is another parameter evaluating the forming quality of rolled ring. A small coaxial tolerance stands for a high forming quality. Figure 12 compared the coaxial tolerance of ring 1 with that of ring 2 . The coaxial tolerance of ring 1 is obviously smaller than that of ring 2 . This indicates that the mandrel feeding strategy proposed in this paper is helpful to improve the coaxiality of the rolled ring.

4.3.3. Plainness. Plainness is also a parameter evaluating the forming quality of rolled ring. The smaller the plainness tolerance is, the higher the forming quality is. Figure 13 compared the plainness tolerance of ring 1 with that of ring 2. It is concluded that the mandrel feeding strategy proposed in this paper is also helpful to improve the plainness of the rolled ring since the plainness tolerance of ring 1 is smaller than that of ring 2 .

4.3.4. Tilting. The ring tilting in rolling process also affects the forming quality of rolled ring. The degree of ring tilting can be denoted by the distance between the center of ring and the symmetric line of rolling mill. Figure 14 shows the comparison of the match degree between rolls with ring 1 and ring 2, where the driven roll is not displayed in Figure 14 for simplification. It can be clearly seen that the match degree of ring 1 is better than that of ring 2 . Figure 15 compared the tilting tolerance of ring 1 with that of ring 2 . Since ring 1 has a smaller tilting tolerance, it can be concluded that a more steady rolling process is carried out by using the mandrel feeding strategy proposed in this paper.

\section{Conclusions}

This paper established the mathematical model of RCRRCDS process. The feeding strategy of constant ring's outer-radiusgrowth-rate in RCRRCDS process was proposed. Plastic penetration condition and biting-in condition were given. Reasonable value range of the mandrel feed rate was deduced. The details of finite element modeling of RCRRCDS process were also given. The main conclusions are drawn as follows.

(1) The theoretical calculation indicates that the mandrel feed rate at $l$ layer-height and at $t$ time, $v_{t}^{\prime}$, should be between $f(l, t)$ and $g(l, t)$ in the whole RCRRCDS process in order to realize a steady forming of RCRRCDS process. If $v_{t}^{\prime}$ is smaller than $f(l, t)$ or near to $f(l, t)$, the ring is difficultly forged penetration in rolling process. If $v_{t}^{\prime}$ is bigger than $g(l, t)$ or near to $g(l, t)$, the ring is difficultly bit into the roll gap in rolling process.

(2) The proposed reasonable value range of the mandrel feed rate in RCRRCDS process was verified by using numerical simulation. The simulation results also indicated that $v_{t}^{\prime}$ should be between $f(l, t)$ and $g(l, t)$ in the whole RCRRCDS process for obtaining a steady forming process. It was found that when $v_{R}$ is equal to $2 \mathrm{~mm} / \mathrm{s}$, the ring is rolled into a nearly round but severely warped ring; when $v_{R}$ is equal to $4 \mathrm{~mm} / \mathrm{s}$, the ring is rolled into a round and plain ring; when $v_{R}$ is equal to $6 \mathrm{~mm} / \mathrm{s}$, the ring is rolled into a nearly round and slightly warped ring. Therefore, the better value of $v_{R}$ is $4 \mathrm{~mm} / \mathrm{s}$.

(3) The proposed mandrel feeding strategy is proved helpful to improve the forming quality of the rolled conical ring. The proposed mandrel feeding strategy and the reasonable value range of mandrel feed rate can provide a guidance for RCRRCDS process.

\section{Conflict of Interests}

The authors declare that there is no conflict of interests regarding the publication of this paper.

\section{Acknowledgment}

This research work is supported by Program for Chang Jiang Scholars and Innovative Research Team in University of Ministry of Education of China (no. IRT0931).

\section{References}

[1] Z. W. Wang, S. Q. Zeng, X. H. Yang, and C. Cheng, "The key technology and realization of virtual ring rolling," Journal of Materials Processing Technology, vol. 182, no. 1-3, pp. 374-381, 2007.

[2] J. Seitz, V. Jenkouk, and G. Hirt, "Manufacturing dish shaped rings on radial-axial ring rolling mills," Production Engineering, vol. 7, pp. 611-618, 2013.

[3] Z. C. Sun, H. Yang, and X. Z. Ou, "Effects of process parameters on microstructural evolution during hot ring rolling of AISI 5140 steel," Computational Materials Science, vol. 49, no. 1, pp. 134-142, 2010.

[4] G. Zhou, L. Hua, D. S. Qian, D. F. Shi, and H. X. Li, "Effects of axial rolls motions on radial-axial rolling process for largescale alloy steel ring with 3D coupled thermo-mechanical FEA," International Journal of Mechanical Sciences, vol. 59, no. 1, pp. 17, 2012.

[5] N. Kim, H. Kim, and K. Jin, "Optimal design to reduce the maximum load in ring rolling process," International Journal of Precision Engineering and Manufacturing, vol. 13, no. 10, pp. 1821-1828, 2012. 
[6] M. Wang, H. Yang, and L. Guo, "Numerical study on motions of rolls in hot rolling of titanium alloy large rings," Rare Metal Materials and Engineering, vol. 41, no. 1, pp. 14-18, 2012.

[7] W. Xu, X. Yang, X. Gong, and J. Zhou, "A new mathematical model for predicting the diameter expansion of flat ring in radial-axial ring rolling," The International Journal of Advanced Manufacturing Technology, vol. 60, pp. 913-921, 2012.

[8] W. Xu, X. Yang, Z. Jiang, and Q. Wang, "Feeding strategy design for steel $42 \mathrm{CrMo}$ in radial-axial ring rolling using processing map," International Journal of Material Forming, pp. 1-8, 2013.

[9] H. L. Yuan, The optimal design of profiled ring blank and the numerical simulation on rolling process [Ph.D. thesis], Huazhong University of Science and Technology, Wuhan,China, 2006.

[10] X.-H. Han, L. Hua, J. Lan, Z.-J. Zuo, G.-W. Jia, and L.-W. Huang, "Simulation and experimental study of hot rolling of LD10 conical ring with inner steps," Journal of Wuhan University of Technology, vol. 29, no. 11, pp. 7-10, 2007.

[11] L. Hua, X. G. Huang, and C. D. Zhu, Theory and Technology of Ring Rolling, Mechanical Industry Press, Beijing, China, 2001.

[12] L. Guo and H. Yang, “Towards a steady forming condition for radial-axial ring rolling," International Journal of Mechanical Sciences, vol. 53, no. 4, pp. 286-299, 2011.

[13] L. B. Pan, On deformation laws and CAPP system for radialaxial ring rolling [Doctoral dissertation], Wuhan University of Technology, Wuhan, China, 2007.

[14] B. Kim, H. Moon, E. Kim, M. Choi, and M. Joun, "A dualmesh approach to ring-rolling simulations with emphasis on remeshing," Journal of Manufacturing Processes, vol. 15, no. 4, pp. 635-643, 2013.

[15] R. S. Lee and H. C. Lin, "Process design based on the deformation mechanism for the non-isothermal forging of Ti-6Al$4 \mathrm{~V}$ alloy," Journal of Materials Processing Technology, vol. 79, pp. 224-235, 1998.

[16] Z. M. Hu, J. W. Brooks, and T. A. Dean, "Experimental and theoretical analysis of deformation and microstructural evolution in the hot-die forging of titanium alloy aerofoil sections," Journal of Materials Processing Technology, vol. 88, no. 1, pp. 251-265, 1999.

[17] K. Shiro, O. Soo-ik, and A. Taylan, Metal Forming and the FiniteElement Method, Oxford University Press, New York, NY, USA, 1989.

[18] M. Wang, H. Yang, Z. C. Sun, and L. G. Guo, "Analysis of coupled mechanical and thermal behaviors in hot rolling of large rings of titanium alloy using 3D dynamic explicit FEM," Journal of Materials Processing Technology, vol. 209, no. 7, pp. 3384-3395, 2009.

[19] Z. M. Hu, J. W. Brooks, and T. A. Dean, "The interfacial heat transfer coefficient in hot die forging of titanium alloy," Proceedings of the Institution of Mechanical Engineers C: Journal of Mechanical Engineering Science, vol. 212, pp. 485-496, 1998.

[20] A. E. Tekkaya, "State-of-the-art of simulation of sheet metal forming," Journal of Materials Processing Technology, vol. 103, no. 1, pp. 14-22, 2000.

[21] K. Davey and M. J. Ward, "A practical method for finite element ring rolling simulation using the ALE flow formulation," International Journal of Mechanical Sciences, vol. 44, no. 1, pp. 165190, 2002. 


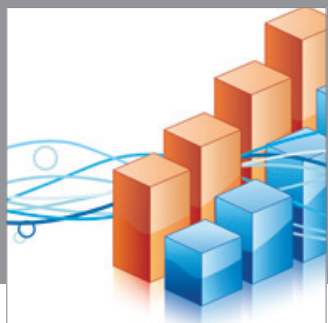

Advances in

Operations Research

mansans

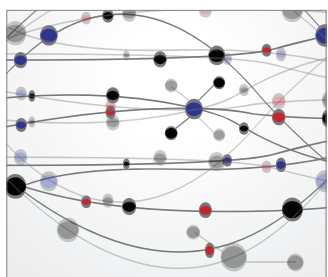

The Scientific World Journal
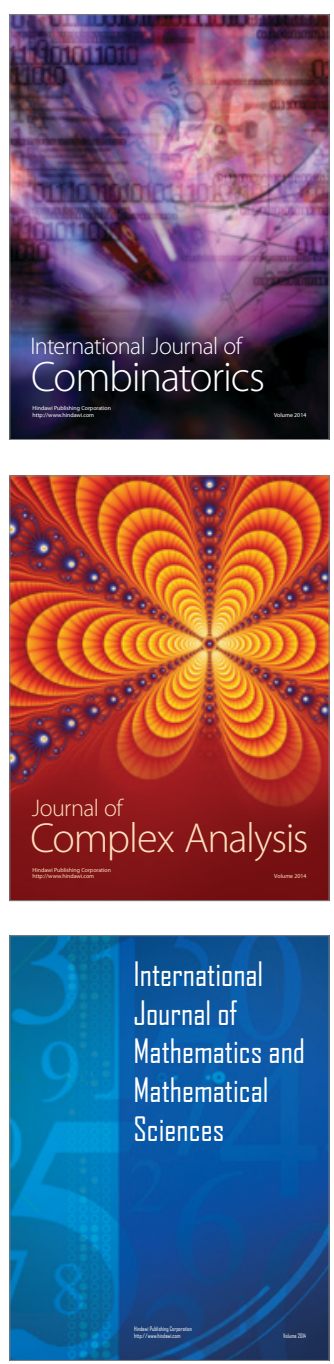
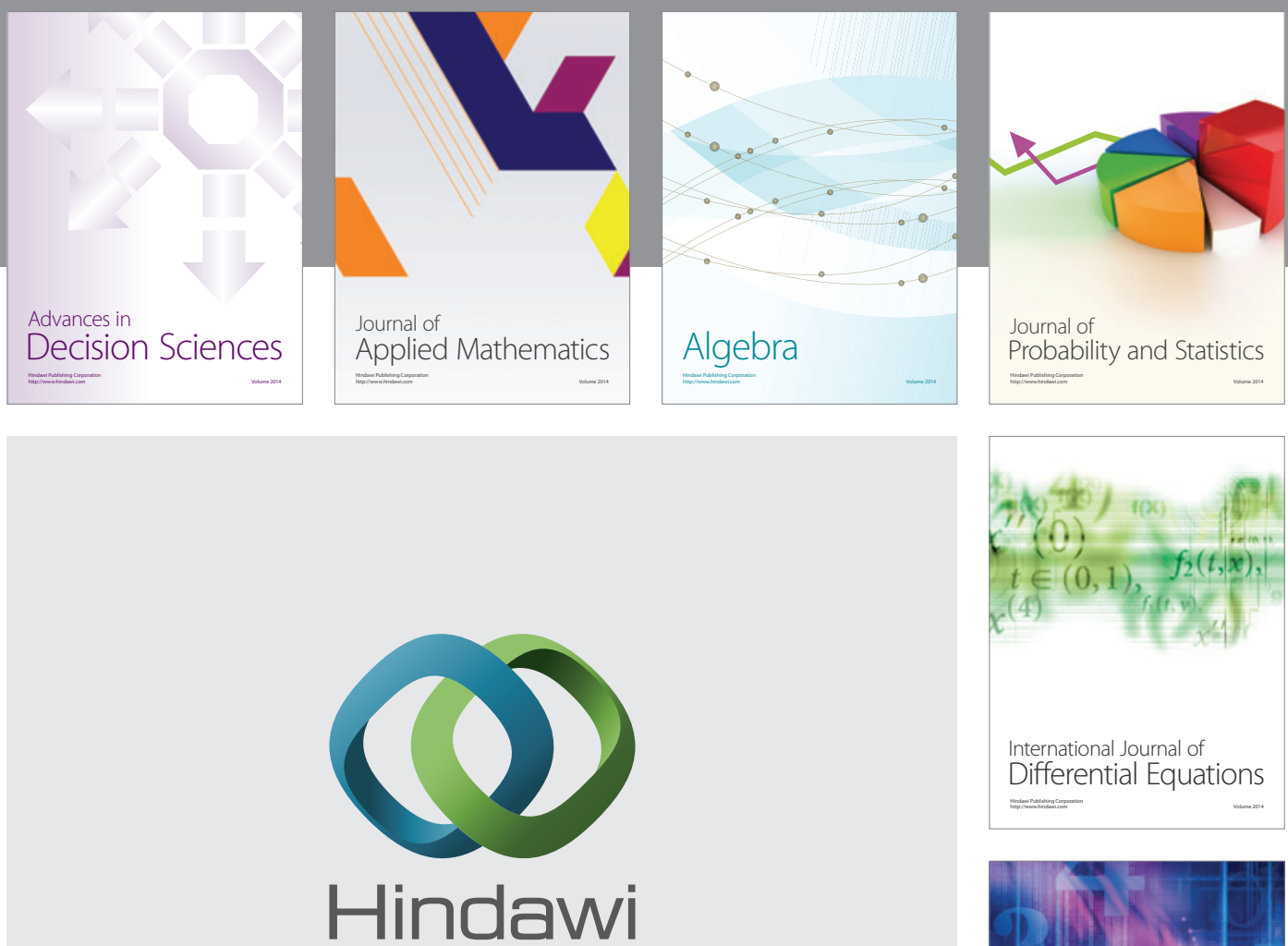

Submit your manuscripts at http://www.hindawi.com
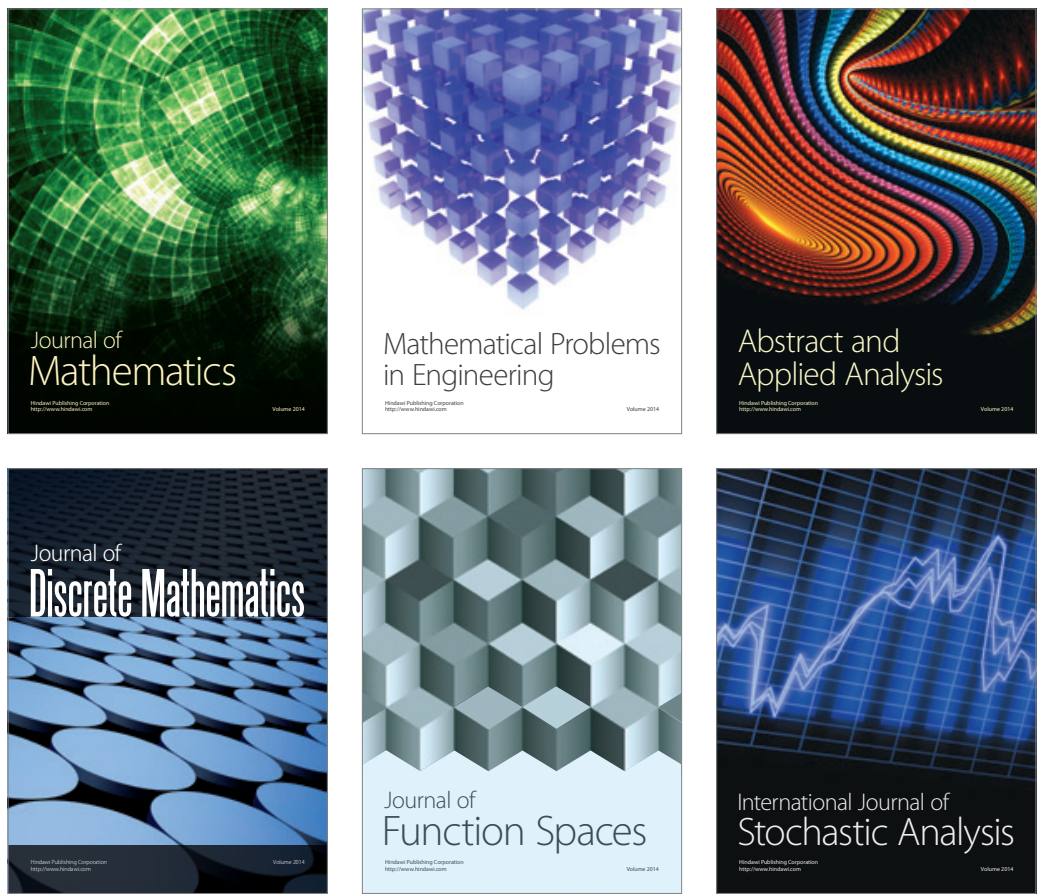

Journal of

Function Spaces

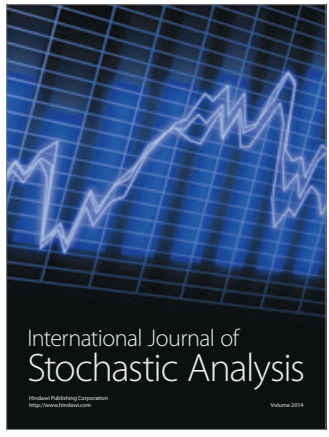

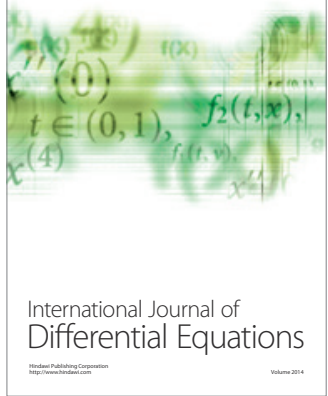
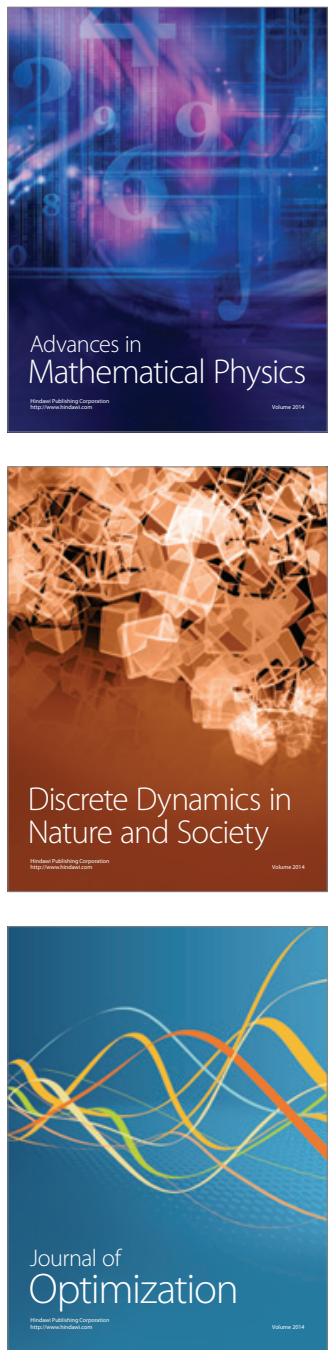